Introduction to the Guest Editors

\title{
Philip Smith, MD, FRCP, FAcadMEd, and Rhys Thomas, BSc, MRCP, MSc, PhD
}

\author{
David M. Greer, MD, MA, FCCM, FAHA, FNCS, FAAN, FANA ${ }^{1}$ \\ ${ }^{1}$ Department of Neurology, Yale University School of Medicine, New \\ Haven, Connecticut
}

Semin Neurol 2015;35:189-190.

The Guest Editors of this issue of Seminars in Neurology are Drs. Philip Smith and Rhys Thomas.

Professor Smith qualified from Liverpool, UK in 1979, which was where he did his general medical training. His clinical neurology training took place in Liverpool, Newcastle-upon-Tyne and Cardiff, UK. After serving as Consultant Neurologist in Cornwall, he returned to Cardiff in 1996 to develop longstanding interests in epilepsy and clinical training. He is currently the lead neurologist in Cardiff and runs the Alan Richens Epilepsy Unit. His research interests include epilepsy genetics, antiepileptic drug management, improving patient communication, and shared decision-making. He is about to take over as President of the Association of British Neurologists, and was past president of the UK Chapter of the International League Against Epilepsy. He has served as coeditor of Practical Neurology since 2011. He is considered a world authority in the field of epilepsy. He also serves on the Editorial Board for Seminars in Neurology.

Dr. Thomas is a Clinical Lecturer from Cardiff, UK. He graduated from Bristol University in 2003 with degrees in medicine and physiology. His major research interests include the genetic etiology of the epilepsies, the relationship between epilepsy and major psychiatric disorders, the epi- demiology of epilepsy, and improving research participation for people with epilepsy. He received an MSc in Psychiatry in 2012, his PhD in epilepsy genetics in 2013, and recently returned from a year as an epilepsy fellow in Melbourne, Australia. He is currently working on trying to find the best research methods to understand the complexity of the genetic generalized epilepsies. He has a particular interest in the genetics of juvenile myoclonic epilepsy and the behavioral features of this unusual epilepsy. He has leading publications in Epilepsia, Nature Reviews Neurology, and Brain. He is an associate editor of Practical Neurology, is joint medical advisor to Epilepsy Professional, and is on the editorial board of Seizure.

We greatly appreciate the efforts of Drs. Smith and Rhys, as well as their all-star group of contributing authors, for their truly remarkable work in this issue of Seminars. The issue provides the reader with an in-depth understanding of this important area in neurology, with great insights into etiologies, genetics, diagnosis, and management. We hope the issue is helpful to you in improving your knowledge of the subject, with practical advice for management and an eye toward the future of research in the field of epilepsy that will improve the care of our patients.
Address for correspondence David M. Greer, MD, MA, FCCM, FAHA, FNCS, Department of Neurology, Yale University School of Medicine, 15 York Street, New Haven, CT 06520-8018

(e-mail: david.greer@yale.edu).
Issue Theme Etiology of Epilepsy; Guest Editors: Philip Smith, MD, FRCP, FAcadMEd, and Rhys Thomas, BSc, MRCP, MSc, PhD
Copyright $\odot 2015$ by Thieme Medical Publishers, Inc., 333 Seventh Avenue, New York, NY 10001, USA. Tel: +1(212) 584-4662.
DOI http://dx.doi.org/ 10.1055/s-0035-1552627. ISSN 0271-8235. 